\title{
Understanding Primary Care Patients' Self-weighing Habits: Cohort Analysis from the PaTH Clinical Data Research Network
}

\author{
Carolyn T. Bramante, MD, MPH', ${ }^{1,2}$ Kathleen M. McTigue, MD, MPH, MS ${ }^{3}$, \\ Harold P. Lehmann, MD, Ph.D. ${ }^{4}$, Jeanne M. Clark, MD, MPH ${ }^{5}$, \\ Scott Rothenberger, Ph.D. ${ }^{3}$, Jennifer Kraschnewski, MD, MPH' , Michelle R. Lent, Ph.D.?, \\ Sharon J. Herring, MD, MPH ${ }^{8}$, Molly B. Conroy, MD, MPH', Jody McCullough, $A A^{6}$, and \\ Wendy L. Bennett, MD, MPH ${ }^{5}$
}

\begin{abstract}
'Division of General Internal Medicine, University of Minnesota, Minneapolis, MN, USA; ${ }^{2}$ Department of Pediatrics, University of Minnesota, Minneapolis, MN, USA; ${ }^{3}$ Division of General Internal Medicine, University of Pittsburgh School of Medicine, Pittsburgh, PA, USA; ${ }^{4}$ Division of Health Informatics, Johns Hopkins School of Medicine, Baltimore, MD, USA; ${ }^{5}$ Division of General Internal Medicine, Johns Hopkins School of Medicine, Baltimore, MD, USA; ${ }^{6}$ Department of Medicine, Penn State University, State College, PA, USA; ${ }^{7}$ Geisinger Health System, Danville, PA, USA; ${ }^{8}$ Center for Obesity Research and Education, Lewis Katz School of Medicine at Temple University, Philadelphia, PA, USA; ${ }^{9}$ Division of General Internal Medicine, University of Utah School of Medicine, Salt Lake City, UT, USA.
\end{abstract}

BACKGROUND: Greater than $60 \%$ of adults have overweight or obesity. Self-weighing is an effective weight loss and weight maintenance tool. However, little is known about self-weighing habits among the primary care patient population. Our objective was to examine the frequency of patient-reported self-weighing, and to evaluate the associations of self-weighing with demographic characteristics and self-monitoring behaviors.

METHODS: We conducted an analysis of survey data collected as part of the PaTH Clinical Data Research Network, which recruited a cohort of 1,021 primary care patients at 4 academic medical centers. Patients of all body mass index (BMI) categories were included.

RESULTS: Response rate of 6-month survey was 727 (71\%). The mean age was 56 years, and most were female $(68 \%)$, White $(78 \%)$, college graduates $(66 \%)$, and employed/retired (85\%). The mean BMI was $30.2 \mathrm{~kg} / \mathrm{m}^{2}$, $80 \%$ of participants had a BMI $\geqq 25 \mathrm{~kg} / \mathrm{m}^{2}$. Of patients with BMI $\geqq 25 \mathrm{~kg} / \mathrm{m}^{2}, 35 \%$ of participants self-weighed weekly and $23 \%$ daily. Participants who reported selfweighing at least weekly were more likely to be older (59 vs 54 years, $p<0.01)$, married $(p=0.01)$, college graduates $(p=0.03)$, White $(p<0.01)$, and employed vs disabled/unemployed $(p<0.01)$. Patients who selfweighed daily had a lower BMI $\left(29 \mathrm{~kg} / \mathrm{m}^{2}\right.$ vs $31 \mathrm{~kg} / \mathrm{m}^{2}$, $p=0.04)$. Patients who tracked exercise or food intake were more likely to self-weigh daily $(p<0.01)$, as were patients wanting to lose or maintain weight $(p<0.01)$.

Prior Presentations This work was presented as a poster presentation at the Society of General Internal Medicine Annual Meeting in Denver, CO, 2018.

Electronic supplementary material The online version of this article (https://doi.org/10.1007/s11606-019-05153-w) contains supplementary material, which is available to authorized users.

Received August 8, 2018

Revised March 5, 2019

Accepted June 5, 2019

Published online July 16, 2019
CONCLUSIONS: Despite its potential for primary and secondary obesity prevention, only $35 \%$ of primary care patients with overweight or obesity engage in selfweighing weekly and less than a quarter (23\%) selfweigh daily. Socioeconomic status appears to be a factor influencing regular self-weighing in this population, potentially contributing to greater health disparities in obesity rates. Patients who self-weighed daily had a lower BMI, suggesting that it may play a role in primary prevention of obesity. More work is needed to explore selfweighing among patients.

KEY WORDS: self-weighing; obesity; weight loss; primary care; selfmonitoring.

J Gen Intern Med 34(9):1775-81

DOI: $10.1007 / \mathrm{s} 11606-019-05153-\mathrm{w}$

(c) Society of General Internal Medicine 2019

\section{BACKGROUND}

Rates of obesity continue to rise in the USA, with $39.6 \%$ of US adults having an obese body mass index (BMI) in 2015-2016, an increase from $33.7 \%$ of adults in 2007-2008. ${ }^{1}$ High rates of overweight and obesity are a public health urgency because of the association with higher medical costs and increased morbidity, including from cardiovascular disease, diabetes, and many forms of cancer. ${ }^{2-6}$ The burden of obesity and cardiovascular disease is particularly high among racial and ethnic minorities. ${ }^{7,8}$

Self-monitoring (e.g., of weight, physical activity, and food intake) is an important component of behavioral weight-loss interventions. ${ }^{9}$ Consistent with Bandura's social learning theory, self-monitoring improves self-awareness, motivation, and self-efficacy, ${ }^{10}$ and there has been a proliferation of technology to support self-monitoring. ${ }^{11}$ Self-weighing is an effective self-monitoring tool during weight loss and weight 
maintenance efforts. ${ }^{12-18}$ As a part of weight-loss interventions, self-weighing daily at home helps individuals identify gains in weight and alter eating and physical activity before the weight gain is significant. ${ }^{12,13,17,18}$ Decreased frequency of self-weighing is associated with weight regain. ${ }^{12,} 13$ Professional organizations (e.g., The Obesity Society and American Heart Association), advise clinicians to recommend selfweighing at least weekly to their patients for the management of obesity and overweight. ${ }^{2,19}$

Despite the effectiveness of self-weighing as a weightmanagement tool, we do not know what percentage of primary care patients weigh themselves regularly. There is potential for primary care clinicians to counsel about self-weighing as part of routine weight management or preventive health care, making it important to first understand typical self-weighing habits among primary care patients, and what characteristics are associated with self-weighing. Using the PaTH Clinical Data Research Network (CDRN) Cohort Study of Healthy Lifestyles, Body Weight and Health Care, we are able to assess information about self-weighing frequency among primary care patients. PaTH is one of the CDRN's in the National Patient-Centered Clinical Research Network (PCORnet). Our objective was to examine the frequency that patients report engaging in self-weighing, and to evaluate associations with demographic and socioeconomic characteristics, as well as clinical characteristics, weight-related goals, and other selfmonitoring behavior. We hypothesized that patients with higher socioeconomic status would be more likely to engage in regular self-weighing, and that patients with a BMI in the normal range would be more likely to self-weigh regularly. Additionally, we were interested in sub-group analyses examining characteristics of self-weighing solely among patients with overweight or obesity.

\section{METHODS}

We conducted a cohort analysis of survey data that was collected as part of the PaTH Cohort Study of Healthy Lifestyles, Body Weight and Health Care. ${ }^{20}$ Institutional Review Board approval was obtained from the PaTH single institutional review board at Johns Hopkins University.

\section{Patient Population and Setting}

We recruited a cohort of adult primary care patients to complete surveys from 7 primary care practices at the 4 MidAtlantic health care systems in the PaTH CDRN-Johns Hopkins University and Health System, Penn State College of Medicine and Medical Center, Temple University Health System, and the University of Pittsburgh Medical Center and Health Plan.

Patients were eligible if they were 18 years of age and had at least 2 weights recorded in the electronic health record (EHR) within the 5-year cohort window, as well as one adult height recorded at any time in the EHR. A 5-year window was chosen because EHR data were only available within this time period from all sites. Patients of all BMI categories were eligible.

Patients were excluded if they were deceased, enrolled in the survey at another institution, or not able to complete the English Language Survey, as the survey was only offered in English.

\section{Recruitment and Enrollment Strategies for the Cohort}

Eligible participants identified via EHR were recruited using letters with a link to online information about the study, an informed consent process, and the web-based survey items. ${ }^{21}$ Four strategies were used to distribute the letters: (1) postal mail for patients without an e-mail address; (2) e-mail for patients with an e-mail address in the EHR; (3) MyChart patient portal for 2 sites with this capability; (4) in-person of a convenience sample of patients who attended clinic visits during the recruitment windows. Participants recruited in person at primary care clinic visits also completed electronic consent, facilitated by research staff. Each health system started recruitment at a different time, and the total recruitment window for all sites was within April 2015 to November 2016. In total, 33,839 patients were approached by all recruitment modalities $(10,706$ by postal mail; 21,273 by e-mail with Redcap survey link; 1,582 by MyChart message; and 278 in person). Recruitment stopped when the goal of recruiting 1,000 patients to fill out the baseline survey was achieved (response rate of $3.0 \%$ ).

\section{Data Collection}

Online, anonymous surveys about sociodemographic background, weight management practices, weight-related interactions with the health system, diet, physical activity, and quality of life using standard survey measures were administered at baseline, 6 , and 12 months post baseline. Please see Appendix 2 online for the 6-month survey.

For this analysis, we focused on self-monitoring practices and restricted our sample to the primary care patients who completed online surveys at baseline and 6-month follow-up because the questions about self-monitoring were asking only in the 6-month survey. We compared those who completed only the baseline survey to those who completed both baseline and 6-month surveys.

\section{Statistical Methods}

Our primary dependent variable of interest was the response to the survey question "How often do you weigh yourself?" Because professional guidelines for management of overweight/obesity recommend self-weighing at least week$1 y,{ }^{2,} 19$ and many weight-loss interventions recommend daily self-weighing, we categorized this variable into "less than weekly" versus "weekly" versus "daily." We then did a subgroup analysis among patients with overweight or obesity in 
Table 1 Characteristics Associated with Daily and Weekly Self-weighing

\begin{tabular}{|c|c|c|c|c|c|}
\hline & $\begin{array}{l}\text { Overall } \\
(n=560)\end{array}$ & $\begin{array}{l}\text { Weighs less than } \\
\text { weekly }(n=233)\end{array}$ & $\begin{array}{l}\text { Weighs weekly } \\
(n=194)\end{array}$ & $\begin{array}{l}\text { Weighs daily } \\
(n=133)^{*}\end{array}$ & $p$ value $* *$ \\
\hline \multicolumn{6}{|l|}{ Demographics } \\
\hline Age in years, mean (SD) & $57(17)$ & $54(16)$ & $56(18)$ & $63(16)$ & $<0.01$ \\
\hline Women, $\mathrm{n}(\%)$ & $386(69)$ & $163(70)$ & $133(69)$ & $90(68)$ & 0.94 \\
\hline Married, n (\%) & $339(61)$ & $127(55)$ & $120(62)$ & $92(69)$ & 0.02 \\
\hline \multicolumn{6}{|l|}{ Race, $n(\%)$} \\
\hline White race & $441(82)$ & $167(75)$ & $156(83)$ & $118(91)$ & $<0.01$ \\
\hline Black race & $71(13)$ & 43 (19) & $23(12)$ & $5(4)$ & \\
\hline Hispanic & $10(2)$ & $5(2)$ & $4(2)$ & $1(1)$ & \\
\hline Asian & $11(2)$ & $7(3)$ & $2(1)$ & $2(2)$ & \\
\hline Other & $6(1)$ & $1(0.5)$ & $2(1)$ & $3(2)$ & \\
\hline \multicolumn{6}{|l|}{ Education, $n(\%)$} \\
\hline High-school degree or less & $46(8)$ & $30(13)$ & $12(6)$ & $4(3)$ & 0.01 \\
\hline Some college or 2-year degree & $123(23)$ & $52(23)$ & $41(22)$ & $30(23)$ & \\
\hline College degree of more & $374(69)$ & $142(63)$ & $137(72)$ & $95(74)$ & \\
\hline \multicolumn{6}{|l|}{ Employment, $n(\%)$} \\
\hline Disabled & $35(6)$ & $24(11)$ & $6(3)$ & $5(4)$ & $<0.01$ \\
\hline Unemployed & $21(4)$ & $11(5)$ & $6(3)$ & $4(3)$ & \\
\hline Student or homemaker & $27(5)$ & $15(7)$ & $8(4)$ & $4(3)$ & \\
\hline Employed (full or part-time) & $312(57)$ & $128(57)$ & $120(63)$ & $64(50)$ & \\
\hline Retired & $148(27)$ & $48(21)$ & $49(26)$ & $51(40)$ & \\
\hline \multicolumn{6}{|l|}{ Health status } \\
\hline $\mathrm{BMI}$ in $\mathrm{kg} / \mathrm{m}^{2}$ mean (SD) & $30(9)$ & $31(9)$ & $31(8)$ & $29(7)$ & 0.04 \\
\hline $\mathrm{BMI} \leq 18$ & $6(1)$ & $3(1)$ & $1(1)$ & $2(2)$ & 0.27 \\
\hline BMI $18.5-24.9$ & $153(30)$ & $63(29)$ & $52(29)$ & $38(32)$ & \\
\hline BMI 25.0-29.9 & $145(28)$ & $59(27)$ & $46(25)$ & $40(33)$ & \\
\hline BMI 30.0-34.9 & $95(18)$ & $32(15)$ & $40(22)$ & $23(19)$ & \\
\hline BMI 35.0-39.9 & $48(9)$ & $25(12)$ & $15(8)$ & $8(7)$ & \\
\hline $\mathrm{BMI} \geq 40.0$ & $70(14)$ & $34(16)$ & $27(15)$ & $9(8)$ & \\
\hline Diabetes, $n(\%)$ & $83(15)$ & $32(14)$ & $36(19)$ & $15(12)$ & 0.40 \\
\hline Prediabetes, $n(\%)$ & $57(11)$ & $24(11)$ & $22(12)$ & $11(9)$ & 0.40 \\
\hline \multicolumn{6}{|l|}{ Weight aspirations, $n(\%)$} \\
\hline Desiring weight gain & $13(2)$ & $9(4)$ & $2(1)$ & $2(2)$ & $<0.01$ \\
\hline Desiring weight maintenance & $118(21)$ & $41(18)$ & $41(21)$ & $36(27)$ & \\
\hline Desiring weight loss & $371(66)$ & $143(61)$ & $138(71)$ & $90(68)$ & \\
\hline Not trying to alter weight & $58(10$ & $40(17)$ & $13(7)$ & $5(4)$ & \\
\hline \multicolumn{6}{|c|}{ Other self-monitoring behavior, $n(\%)$} \\
\hline Tracks exercise & $291(52)$ & $91(39)$ & $121(63)$ & $79(60)$ & $<0.01$ \\
\hline Tracks food intake & $335(60)$ & $107(46)$ & $130(67)$ & $98(74)$ & $<0.01$ \\
\hline
\end{tabular}

*Includes the 2 participants who weigh more than once per day

**p value from bivariate analysis using chi-square or ANOVA as appropriate BMI, body mass index

order to understand how many patients meet recommended self-weighing frequency for weight loss. ${ }^{2,19}$ We describe the small subset of patients who desire weight gain.

We explored several independent variables (e.g., age, race, education) and their relationship to our dependent variable of interest, self-weighing frequency. We performed descriptive analyses of sociodemographic baseline characteristics to assess differences between patients who self-weigh daily and weekly and those who do not using chi-square and ANOVA. We collapsed several of the independent variables into meaningful categories for ease of interpretation and small numbers of participants in some cells (e.g., "Out of work for more than one year" and "Out of work for less than one year" into "Unemployed").

BMI was assessed using self-reported height and weight from the baseline survey. We used chi-square tests to explore whether weight-related goals (desire for weight loss, weight maintenance, or weight gain) or other self-monitoring behaviors (of food intake or physical activity) were associated with self-weighing at least weekly. We used logistic regression to model the association between self-weighing and sociodemographic and clinical characteristics based on variables we identified a priori from previous research that might influence one's self-weighing frequency. We tested for interaction by race, education, and employment.

Two-sided $p \leqq 0.05$ was considered statistically significant. Analyses were performed using STATA statistical software version 15 (StataCorp LP, College Station, TX).

\section{RESULTS}

Of 1,021 patients who completed a baseline survey, 727 (71\%) completed a 6-month survey and were included in this analysis. Site-specific follow-up rates ranged from 35 to $86 \%$ across the 4 sites. While those with follow-up data were similar to those without in a number of factors, participants who completed both surveys were more likely to be younger, married, and identify their race as White (Appendix Table 1 online). The percentage of missingness for the question about selfweighing ranged from 0 to $44 \%$ per site. 
Table 2 Odds of Self-weighing at Least Weekly

\begin{tabular}{|c|c|c|c|}
\hline & $\begin{array}{l}\text { Crude } \\
\text { OR }\end{array}$ & $\begin{array}{l}\text { Adjusted } \\
\text { OR* }\end{array}$ & $\begin{array}{l}95 \% \text { confidence } \\
\text { intervals for } \\
\text { aOR }\end{array}$ \\
\hline \multicolumn{4}{|l|}{ Demographics } \\
\hline Age $<50$ years old & 1.0 & 1.0 & - \\
\hline Age $>50$ years old & 1.9 & 1.6 & 1.0 to $2.6^{* *}$ \\
\hline Men & 1.0 & 1.0 & - \\
\hline Women & 0.9 & 1.2 & 0.8 to 1.8 \\
\hline Unmarried & 1.0 & 1.0 & - \\
\hline Married & 1.5 & 1.3 & 0.9 to 2.0 \\
\hline \multicolumn{4}{|l|}{ Race/ethnicity } \\
\hline Asian & Ref & Ref & - \\
\hline Black race & 1.1 & 2.1 & 0.5 to 8.7 \\
\hline Hispanic & 1.8 & 2.4 & 0.4 to 15.7 \\
\hline White race & 2.8 & 2.9 & 0.8 to 10.8 \\
\hline Other & 1.8 & 2.8 & 0.1 to 65.0 \\
\hline \multicolumn{4}{|l|}{ Education } \\
\hline $\begin{array}{l}\text { High-school } \\
\text { degree or less }\end{array}$ & Ref & Ref & - \\
\hline Some college & 2.6 & 2.5 & 1.1 to $5.8^{* *}$ \\
\hline $\begin{array}{l}\text { or 2-year degree } \\
\text { At least college degree }\end{array}$ & 3.0 & 2.8 & 1.3 to $6.1 * * *$ \\
\hline \multicolumn{4}{|l|}{ Employment } \\
\hline Disabled & Ref & Ref & - \\
\hline Not employed & 2.0 & 2.0 & 0.6 to 6.8 \\
\hline Student or homemaker & 1.7 & 1.4 & 0.4 to 5.0 \\
\hline $\begin{array}{l}\text { Employed } \\
\text { (full or part-time) }\end{array}$ & 3.1 & 2.6 & 1.0 to $6.6^{* *}$ \\
\hline $\begin{array}{l}\text { (Iuil or part-time) } \\
\text { Retired }\end{array}$ & 4.5 & 3.1 & 1.2 to $8.1 * *$ \\
\hline \multicolumn{4}{|l|}{ Health status } \\
\hline $\mathrm{BMI}<30$ & 1.0 & 1.0 & - \\
\hline $\mathrm{BMI} \geq 30$ & 0.9 & 1.0 & 0.7 to 1.5 \\
\hline Has diabetes & 1.0 & 1.0 & - \\
\hline Does not have & 0.8 & 0.8 & 0.5 to 1.5 \\
\hline \multicolumn{4}{|l|}{ diabetes } \\
\hline Has prediabetes & 0.9 & 0.9 & 0.4 to 1.9 \\
\hline
\end{tabular}

*Adjusted for the other variables (age, sex, marital status, race, education, employment, diabetes, and obesity) through logistic regression

$* * p \leq 0.05, * * * p \leq 0.01$

aOR, adjusted odds ratio; BMI, body mass index

The mean age was 57 years, and 69\% were female. Most participants identified as White (82\%), with $13 \%$ identifying as Black, $2 \%$ as Hispanic, $2 \%$ as Asian, and $1 \%$ as other. The majority of participants were college graduates (69\%), and $51 \%$ had more than a college degree. Most participants (56\%) were employed or self-employed, and $27 \%$ were retired. The mean BMI was $30.2 \mathrm{~kg} / \mathrm{m}^{2}$. Forty-one percent of participants had obesity $\left(\mathrm{BMI} \geq 30 \mathrm{~kg} / \mathrm{m}^{2}\right), 28 \%$ had overweight (BMI $\geq 25 \mathrm{~kg} / \mathrm{m}^{2}$, Table 1).

Thirty-five percent of respondents reported self-weighing weekly and $24 \%$ daily. In unadjusted analyses (Table 1), participants who reported self-weighing daily were older than those who weighed weekly or less than weekly (63 years vs 56 years vs 54 years, respectively) $(p<0.01)$. Participants who weighed daily or weekly were more likely to be married $(p=0.02)$. Ninety-one percent of participants who self-weighed daily were White, compared to $83 \%$ of those who weighed weekly and $75 \%$ of those who weighed less than weekly $(p<0.01)$. Participants who self-weighed daily were more likely to have more than a college degree (74\%), and those who self-weighed less than weekly were more likely to have a high-school degree or less $(13 \%)(p<0.01)$. Participants who self-weighed daily were more likely to be retired, those who weighed weekly were more likely to be employed, and those who weighed less than weekly were more likely to be disabled or unemployed $(p<0.01)$. Participants who weighed daily had a lower BMI than those who weighed weekly or less than weekly $\left(29 \mathrm{~kg} / \mathrm{m}^{2}\right.$ vs $31 \mathrm{~kg} /$ $\mathrm{m}^{2}$ vs $31 \mathrm{~kg} / \mathrm{m}^{2}$, respectively, $p=0.04$ ).

Regarding other self-monitoring behaviors, $52 \%$ of participants reported tracking their exercise and 60\% reported tracking their food intake. Patients who tracked their exercise or food intake were more likely to self-weigh at least weekly $(p<0.01$ for both).

Overall, $66 \%$ of the cohort desired weight loss, and $21 \%$ desired weight maintenance (Table 1). Patients who reported wanting to lose weight or stay in the same weight were more likely to self-weigh at least weekly $(p<0.01)$. Seventeen percent of participants with an overweight BMI, and $6 \%$ of participants with an obese BMI, desired to keep their weight the same. Patients desiring weight loss or weight maintenance were more likely to self-weigh at least weekly $(p<0.01)$. Individuals wanting to gain weight $(n=13)$ were more likely to be a minority $(p<0.01)$, retired $(p<0.01)$, have a normal BMI $(p<0.01)$, not have diabetes $(p=0.04)$, and have some college or 2 -year education $(p<0.01)$. They were less likely to track their exercise or food intake ( $p<0.01$ for both).

In regression analyses, predictors of self-weighing at least weekly were older age, higher education, and being employed or retired. There was no difference by marital status, sex, race, BMI category, or diagnosis of diabetes (Table 2). Confirming the adjusted analyses, the predicted probability of self-weighing at least weekly was significantly greater for participants who were employed/ retired versus not employed, patients over age 50, patients with a college degree or more, and patients desiring weight loss compared to patients desiring weight maintenance or patients who were not trying to alter their weight (Figs. 1 and 2). There was no evidence of interaction by race, education, and employment.

In sub-group analyses of individuals who had overweight or obesity, $23 \%$ of patients engaged in daily selfweighing and $35 \%$ engaged in weekly self-weighing. Participants who self-weighed daily were more likely to be older $(p<0.01)$, be White $(p=0.01)$, have a college degree or more $(p<0.01)$, be retired $(\mathrm{p}<0.01)$, and have a lower BMI, $32 \mathrm{~kg} / \mathrm{m}^{2}$ compared to $35 \mathrm{~kg} / \mathrm{m}^{2}$, among those who self-weighed less than weekly (Table 3). Participants who weighed weekly or daily were also more likely to desire weight loss $(p<0.01)$, and to track their exercise or food intake $(p<0.01)$.

\section{DISCUSSION}

To our knowledge, this manuscript is the first paper to examine self-weighing frequency among primary care 


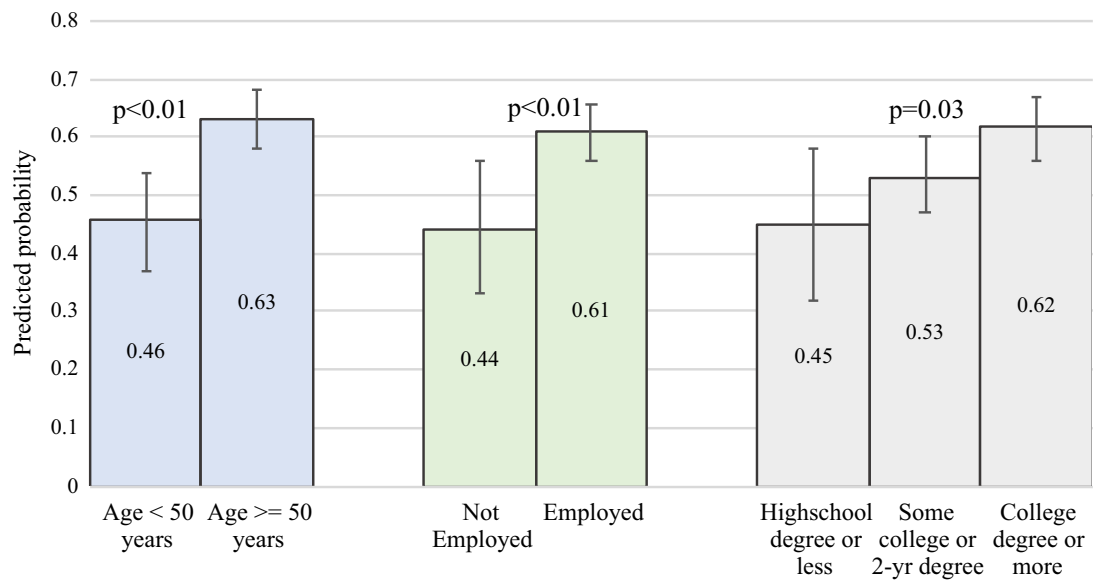

Figure 1 Predicted probability of self-weighing at least weekly*. Adjusted for age, race, BMI, marital status, and employment, education, or sex as appropriate. Bars represent $95 \%$ confidence intervals.

patients in the USA. We found that only $35 \%$ of primary care patients engage in self-weighing weekly, and less than a quarter $(24 \%)$ in daily self-weighing. These results were similar for the sub-group of adults with overweight or obesity (35\% and $23 \%$, respectively). Notably, participants who self-weighed daily had a significantly lower BMI, both in the whole cohort and the sub-group with overweight or obesity. However, we cannot infer causality between self-weighing daily causing weight loss and lower BMI, as BMI was reported at the baseline survey, and self-weighing frequency was reported 6 months later. Self-weighing was associated with a desire to lose or maintain weight. Patients were more likely to weigh at least weekly if they also tracked food intake or exercise. The survey used a validated tool for assessing selftracking behaviors, ${ }^{22}$ but this tool does not assess exactly how food intake and exercise were tracked. However, given the prevalence of apps and devices for tracking steps and calories, it is possible that patients might understand "tracking" to mean on electronic devices. Selfweighing at least weekly was also associated with markers of high economic status (White race, higher levels of education, and being employed), among the full cohort as well as in the sub-group of patients with overweight or obesity.

Self-weighing has been shown to be an effective component of behavioral weight-loss interventions, ${ }^{9}, 12,17$ both for weight loss and maintenance of weight loss, ${ }^{13-15}$ making it important to understand current self-monitoring practices among primary care patients. Our findings suggest that a significant portion of primary care patients, and specifically patients with overweight/obesity, are not engaging in this key behavioral intervention recommended by professional societies for the management of overweight and obesity. ${ }^{2,} 19$ Some patients did desire weight gain despite having a normal BMI, and while we cannot make conclusions about this subset of patients

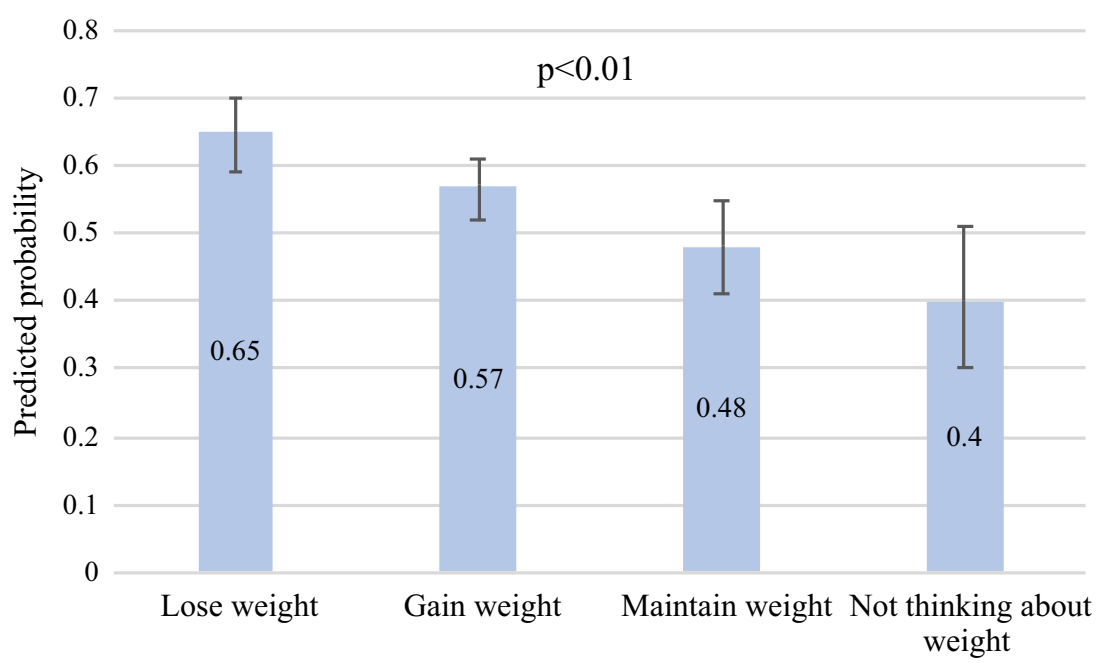

Figure 2 Predicted probability of self-weighing at least weekly based on weight aspiration*. Adjusted for age, sex, race, BMI, marital status, employment, and education Bars represent $95 \%$ confidence intervals. 
Table 3 Characteristics Associated with Daily and Weekly Self-weighing Among Patients with Overweight or Obesity (BMI $\left.\geq 25 \mathrm{~kg} / \mathrm{m}^{2}\right)$

\begin{tabular}{|c|c|c|c|c|c|}
\hline & $\begin{array}{l}\text { Overall } \\
(n=401)\end{array}$ & $\begin{array}{l}\text { Weighs less than } \\
\text { weekly }(n=167)\end{array}$ & $\begin{array}{l}\text { Weighs weekly } \\
(n=141)\end{array}$ & $\begin{array}{l}\text { Weighs daily } \\
(n=93)\end{array}$ & $p$ value $*$ \\
\hline \multicolumn{6}{|l|}{ Demographics } \\
\hline Age in years, mean (SD) & $57(16)$ & $54(16)$ & $55(16)$ & $63(15)$ & $<0.01$ \\
\hline Women, $n(\%)$ & $264(66)$ & $112(67)$ & $93(66)$ & $59(64)$ & 0.86 \\
\hline Married, $n(\%)$ & $232(58)$ & $88(53)$ & $83(59)$ & $61(66)$ & 0.13 \\
\hline \multicolumn{6}{|l|}{ Race, $n(\%)$} \\
\hline White race & $303(79)$ & $114(72)$ & $106(79)$ & $81(91)$ & \multirow[t]{5}{*}{0.01} \\
\hline Black race & $67(17)$ & $39(25)$ & $23(17)$ & $5(5)$ & \\
\hline Hispanic & $8(2)$ & $4(3)$ & $3(2)$ & $1(1)$ & \\
\hline Asian & $4(1)$ & $2(1)$ & $2(1)$ & $0(0)$ & \\
\hline Other & $3(1)$ & $0(0)$ & $1(1)$ & $2(2)$ & \\
\hline \multicolumn{6}{|l|}{ Education, $n(\%)$} \\
\hline High-school degree or less & $38(10)$ & $26(16)$ & $10(7)$ & $2(2)$ & \multirow[t]{3}{*}{$<0.01$} \\
\hline Some college or 2-year degree & $102(26)$ & $41(26)$ & $36(26)$ & $25(28)$ & \\
\hline College degree or more & $245(64)$ & $92(58)$ & $91(66)$ & $62(70)$ & \\
\hline \multicolumn{6}{|l|}{ Employment, $n(\%)$} \\
\hline Disabled & $30(8)$ & $22(14)$ & $5(4)$ & $3(3)$ & \multirow[t]{5}{*}{$<0.01$} \\
\hline Unemployed & $16(4)$ & $9(6)$ & $5(4)$ & $2(2)$ & \\
\hline Student or homemaker & $13(3)$ & $6(4)$ & $4(3)$ & $3(3)$ & \\
\hline Employed (full or part time) & $228(59)$ & $89(56)$ & $90(66)$ & $49(55)$ & \\
\hline Retired & $99(26)$ & $34(21)$ & $33(24)$ & $32(36)$ & \\
\hline \multicolumn{6}{|l|}{ Health status } \\
\hline BMI in $\mathrm{kg} / \mathrm{m}^{2}$, mean (SD) & $34(8)$ & $35(9)$ & $34(8)$ & $32(6)$ & 0.02 \\
\hline BMI $25.0-29.9$ & $145(41)$ & $59(39)$ & $46(36)$ & $40(50)$ & \multirow[t]{4}{*}{0.09} \\
\hline BMI 30.0-34.9 & $95(27)$ & $32(21)$ & $40(31)$ & $23(29)$ & \\
\hline BMI 35-39.9 & $48(13)$ & $25(17)$ & $15(12)$ & $8(10)$ & \\
\hline $\mathrm{BMI} \geq 40$ & $70(20)$ & $34(23)$ & $27(21)$ & $9(11)$ & \\
\hline Diabetes, $n(\%)$ & $74(19)$ & $29(18)$ & $31(23)$ & $14(16)$ & 0.72 \\
\hline Prediabetes, $n(\%)$ & $47(12)$ & $21(13)$ & $16(12)$ & $10(11)$ & 0.72 \\
\hline \multicolumn{6}{|l|}{ Weight aspirations, $n(\%)$} \\
\hline Desiring weight gain & $2(0.5)$ & $1(1)$ & $0(0)$ & $1(1)$ & \multirow[t]{5}{*}{$<0.01$} \\
\hline Desiring weight maintenance & $51(13)$ & $17(10)$ & $16(11)$ & $18(19)$ & \\
\hline Desiring weight loss & $313(78)$ & $123(74)$ & $118(84)$ & $72(77)$ & \\
\hline Not trying to alter weight & $35(9)$ & $26(16)$ & $7(5)$ & $2(2)$ & \\
\hline \multicolumn{5}{|c|}{ Other self-monitoring behavior, n (\%) } & \\
\hline Tracks exercise & $206(52)$ & $64(39)$ & $89(63)$ & $53(58)$ & $<0.01$ \\
\hline Tracks food intake & $247(62)$ & 77 (46) & $99(70)$ & $71(76)$ & $<0.01$ \\
\hline
\end{tabular}

*p value from bivariate analysis using chi-square or ANOVA as appropriate

BMI, body mass index

because the number was small, clinicians could consider screening for weight goals in patients of all BMI categories and counsel against weight gain if not appropriate.

Clinicians could play a role in recommending and facilitating self-weighing for patients with overweight or obesity who desire weight loss or weight maintenance. Prior research has shown that primary care clinicians feel they lack effective strategies to help patients lose and maintain weight. ${ }^{23}$ Advising patients to self-weigh could be a simple and realistic component to add to the routine weight management counseling done in busy primary care settings. It is possible that socioeconomic status may be a factor influencing regular self-weighing in this population of primary care patient. We have not found literature that assesses barriers to self-weighing among primary care patients, and our findings indicate that future work is needed in this area. We have not found literature assessing self-weighing in primary prevention of obesity, but our findings that patients who self-weigh daily had a lower BMI may indicate that self-weighing could play a role in primary prevention of weight gain; more research is needed to better understand this.

This study has several limitations. The surveys did not assess whether patients owned a scale, or had regular access to a scale elsewhere, and scale access may affect self-weighing frequency. Additionally, the surveys did not assess for history of congestive heart failure, a condition for which patients are advised to self-weigh regularly. However, because the prevalence of congestive heart failure is approximately $1-2 \%$ of the general adult population below age $65,{ }^{24}$ and the average age of our sample was 57 years, we do not feel that patients with CHF would significantly affect these self-weighing frequency results. While our success at recruiting from a variety of clinical practices in the mid-Atlantic region helped ensure that a range of perspectives were represented, the generalizability of our findings is limited by the fact that participants were primarily White, college-educated, and employed. The question assessing self-weighing frequency was only assessed at the 6-month survey, so it is difficult to understand whether patients changed self-weighing frequency based on changes in weight status. The site-specific follow-up rates ranged from 35 to $86 \%$, and the rate of missingness of the question about self-weighing ranged from 0 to $46 \%$, overall $23 \%$. Lastly, the height and weight data were self-reported, which may lead to underestimated BMIs. $^{25}$ 


\section{CONCLUSIONS}

Despite its potential for primary and secondary obesity prevention, only $35 \%$ of primary care patients with overweight or obesity engage in self-weighing weekly and less than a quarter $(23 \%)$ self-weigh daily. Socioeconomic status appears to be a factor influencing regular self-weighing in this population, potentially contributing to greater health disparities in obesity rates. Self-weighing was associated with a desire to lose or maintain weight and with other weight-related self-monitoring behaviors. More work is needed to understand whether patients own scales in their home and whether such ownership affects self-weighing behavior, and to design interventions to encourage selfweighing among patients with elevated BMI who desire weight loss.

Funding Source: This work was funded through a Patient-Centered Outcomes Research Institute (PCORI) Award (PCORI CDRN no. 130604912) for development of the National Patient-Centered Clinical Research Network, known as PCORnet. Dr. Bramante was funded by the Behavioral Research in Heart and Vascular Disease Program Fellowship Training Program (T32HL007180-41A1; PI: Levine, David). The views presented in this article are solely the responsibility of the author(s) and do not necessarily represent the views of the PatientCentered Outcomes Research Institute (PCORI), its Board of Governors or Methodology Committee, or other participants in PCORnet.

Corresponding Author: Carolyn T. Bramante, MD, MPH; Department of PediatricsUniversity of Minnesota, Minneapolis, MN, USA

\section{Compliance with Ethical Standards:}

Conflict of Interest: The authors declare that they do not have a conflict of interest.

Prior Presentations: This work was presented as a poster presentation at the Society of General Internal Medicine Annual Meeting in Denver, CO, 2018.

\section{REFERENCES}

1. Hales CM, Fryar CD, Carroll MD, Freedman DS, Ogden CL. Trends in Obesity and Severe Obesity Prevalence in US Youth and Adults by Sex and Age, 2007-2008 to 2015-2016. JAMA. 2018;319(16):1723-1725.

2. Jensen MD, Ryan DH, Apovian CM, et al. 2013 AHA/ACC/TOS guideline for the management of overweight and obesity in adults: a report of the American College of Cardiology/American Heart Association Task Force on Practice Guidelines and The Obesity Society. J Am Coll Cardiol. 2014;63(25 Pt B):2985-3023.

3. Macumber I, Schwartz S, Leca N. Maternal obesity is associated with congenital anomalies of the kidney and urinary tract in offspring. Pediatr Nephrol. 2016.

4. Mitchell A, Fantasia HC. Understanding the Effect of Obesity on Fertility Among Reproductive-Age Women. Nurs Womens Health. 2016;20(4):368-376.

5. Simeone RM, Tinker SC, Gilboa SM, et al. Proportion of selected congenital heart defects attributable to recognized risk factors. Ann Epidemiol. 2016;26(12):838-845.
6. Flegal KM, Graubard BI, Williamson DF, Gail MH. Cause-specific excess deaths associated with underweight, overweight, and obesity. JAMA. 2007;298(17):2028-2037.

7. Go AS, Mozaffarian D, Roger VL, et al. Heart disease and stroke statistics-2014 update: a report from the American Heart Association. Circulation. 2014;129(3):e28-e292.

8. Flegal KM, Kruszon-Moran D, Carroll MD, Fryar CD, Ogden CL. Trends in Obesity Among Adults in the United States, 2005 to 2014. JAMA. 2016;315(21):2284-2291.

9. Burke LE, Wang J, Sevick MA. Self-monitoring in weight loss: a systematic review of the literature. J Am Diet Assoc. 2011;111(1):92-102.

10. Bandura A, Schunk DH. Cultivating competence, self-efficacy, and intrinsic interest through proximal self-motivation. J Pers Soc Psychol. 1981;41(3):586-598.

11. Kozak AT, Buscemi J, Hawkins MA, et al. Technology-based interventions for weight management: current randomized controlled trial evidence and future directions. J Behav Med. 2017;40(1):99-111.

12. Butryn ML, Phelan S, Hill Jo, Wing RR. Consistent self-monitoring of weight: a key component of successful weight loss maintenance. Obesity (Silver Spring, Md). 2007;15(12):3091-3096.

13. Helander EE, Vuorinen AL, Wansink B, Korhonen IK. Are breaks in daily self-weighing associated with weight gain? PloS One. 2014;9(11):e113164.

14. VanWormer JJ, Martinez AM, Martinson BC, et al. Self-weighing promotes weight loss for obese adults. Am J Prev Med. 2009;36(1):70-73.

15. Zheng Y, Klem ML, Sereika SM, Danford CA, Ewing LJ, Burke LE. Selfweighing in weight management: a systematic literature review. Obesity (Silver Spring, Md). 2015;23(2):256-265.

16. Painter SL, Ahmed R, Hill Jo, et al. What Matters in Weight Loss? An In-Depth Analysis of Self-Monitoring. J Med Internet Res. 2017;19(5):e160.

17. Steinberg DM, Bennett GG, Askew S, Tate DF. Weighing every day matters: daily weighing improves weight loss and adoption of weight control behaviors. J Acad Nutr Diet. 2015;115(4):511-518.

18. Steinberg DM, Tate DF, Bennett GG, Ennett S, Samuel-Hodge C, Ward DS. The efficacy of a daily self-weighing weight loss intervention using smart scales and e-mail. Obesity (Silver Spring). 2013;21(9):1789-1797.

19. Garvey WT, Mechanick JI, Brett EM, et al. American association of clinical endocrinologists and american college of endocrinology comprehensive clinical practice guidelines for medical care of patients with obesity. Endocr Pract. 2016;22 Suppl 3:1-203.

20. Amin W, Tsui FR, Borromeo C, et al. PaTH: towards a learning health system in the Mid-Atlantic region. $J$ Am Med Inform Assoc. 2014;21(4):633-636.

21. Harris PA, Taylor R, Thielke R, Payne J, Gonzalez N, Conde JG. Research electronic data capture (REDCap)-A metadata-driven methodology and workflow process for providing translational research informatics support. J Biomed Inform. 2009;42(2):377-381.

22. Vitolins MZ, Anderson AM, Delahanty L, et al. Action for Health in Diabetes (Look AHEAD) trial: baseline evaluation of selected nutrients and food group intake. J Am Diet Assoc. 2009; 109(8):1367-1375.

23. Steeves JA, Liu B, Willis G, Lee R, Smith AW. Physicians' personal beliefs about weight-related care and their associations with care delivery: The U.S. National Survey of Energy Balance Related Care among Primary Care Physicians. Obes Res Clin Pract. 2015;9(3):243-255.

24. Roger VL. Epidemiology of heart failure. Circ Res. 2013;113(6):646-659.

25. Maukonen M, Mannisto S, Tolonen H.. A comparison of measured versus self-reported anthropometrics for assessing obesity in adults: a literature review. Scand J Public Health. 2018;46(5):565-579.

Publisher's Note Springer Nature remains neutral with regard to jurisdictional claims in published maps and institutional affiliations. 